\title{
La construcción de la mirada museográfica. El Antimanual del museólogo de Lauro Zavala
}

\author{
Norma Angélica Ávila Meléndez
}

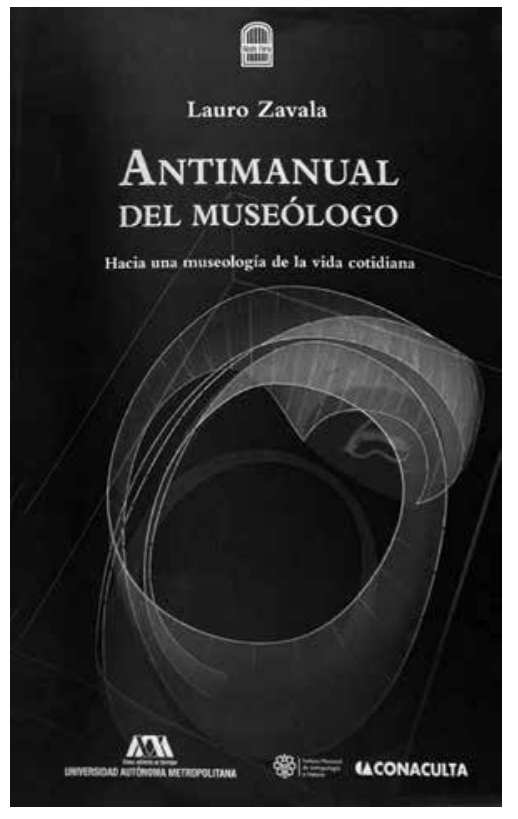

FIGURA 1. Portada del Antimanual del museólogo. Hacia una museología de la vida cotidiana, Lauro Zavala, México, UAM/INAH/Conaculta, 2012.
E I autor de este Antimanual... también ha escrito acerca del arte de ela- borar reseñas, así que retomando sus sugerencias, esta reseña fue escrita pensando en los lectores, particularmente en los jóvenes investigadores del campo museológico.

El Antimanual del museólogo (Figura 1) reúne secciones de otros libros, así como artículos y conferencias escritos a lo largo de dos décadas por Lauro Zavala, un reconocido investigador en muy diversas áreas, como la semiótica y el análisis literario y cinematográfico, pilares sobre los que ha construido un enfoque transdisciplinar en el que vincula creativamente categorías y herramientas metodológicas. De su vasta producción - que exigiría un estudio exhaustivo-, tanto los artículos que abordan aspectos epistemológicos como sus estudios sobre el tema de la recepción en otros campos ayudan a esclarecer su teoría de la recepción museográfica (Zavala 2001).

En el prólogo de la obra, Zavala advierte que su carácter de antimanual se produce porque no es una guía de recomendaciones prácticas ni un conjunto de casos ejemplares, ni desarrolla el punto de vista del equipo de producción: su apuesta es por la apertura al debate y la visibilización de los vacíos de conocimiento. En el Antimanual del museólogo, integrado por un prólogo, tres secciones, la conclusión y los anexos, propone tres "salas" que no exigen una lectura lineal. El lector, de acuerdo con sus propios intereses, puede acercarse a él de modo aleatorio y fragmentario.

La primera sala plantea conceptos fundamentales para una teoría de la recepción museográfica; los modelos para estudiarla, se presentan en la segunda sala —la medular, según el autor-, para, en la tercera, hacer un apunte sobre las consecuencias de tomar la experiencia del visitante como directriz en el diseño de los espacios museográficos. A pesar de que la segunda sala sea la esencial, si el lector quiere ubicar todos los elementos de cada modelo tendrá que revisar con detalle las tres secciones, pues a lo largo de ellas aparecen los puntos nodales de la propuesta.

Para sintetizar el planteamiento de Zavala, propongo considerar tres ejes reflexivos. El primero es la valoración del visitante como el patrimonio más valioso, la cual exige una transformación de los modos tanto de producción museográfica como de observación de los espacios cotidianos. Toda la 
construcción teórica de Zavala está sustentada en esta idea, que se contrapone con la visión de muchos profesionales de museos, que trabajan desde una visión disciplinar, una legitimación institucional y/o un conocimiento no sistemático de los visitantes y del papel que éstos juegan en la comunicación museográfica.

El segundo eje transita por el reconocimiento de tres dimensiones para el estudio de la experiencia museográfica: lo ritual, lo lúdico y lo educativo. El Antimanual subraya que la dimensión educativa surge de la relación entre las otras dos, la ritual y la lúdica, es decir, del equilibrio entre lo no cotidiano y la voluntad de juego, aspecto en el que los primeros textos de Zavala no enfatizaban.

El tercer eje es el establecimiento de cuatro modelos transdisciplinares para estudiar dicha experiencia: uno paradigmático, que da cuenta de la especificidad de la experien- cia museográfica; uno sintagmático, para reconocer los componentes secuenciales de la visita; otro más, para la reconstrucción narrativa de la experiencia y, por último, un modelo general sobre los espacios. A diferencia de los tres primeros, este último no había sido nombrado antes; de hecho, Zavala no avanza más en este texto, sino que se limita a señalar su posibilidad (Figura 2).

Al condensar estas propuestas en un solo libro, los investigadores de las nuevas generaciones advertirán el valor que supone abrir nuevos espacios conceptuales para el ámbito museológico. No deja de sorprender que a Zavala, un autor transdisciplinar — ¿o será precisamente por ello?-, se lo considere un investigador que trabaja "fuera" del campo, y que a pesar de la importancia de sus ideas sean más bien escasos los estudios académicos dentro de la museología que apliquen - $\mathrm{O}$ refuten- los modelos de análisis que propone.

El Antimanual del museólogo, resultado de un ciclo reflexivo entre los años 1992 y 2008, es una obra imprescindible por ser una producción netamente teórica, pensada en español, en el contexto mexicano. Zavala es el autor principal de Posibilidades y límites de la comunicación museográfica, libro publicado en 1993 y, por lo tanto, contemporáneo del de Falk y Dierking, The Museum Experience, que apareció un año antes. Más adelante, Hooper-Greenhill publicaría dos libros que se volverían clásicos: The Museum and Their Visitors (1994) y The Educational Role of Museum (1994), año en que Zavala, junto con Roger Miles, editó una compilación de autores europeos titulada Towards the Museum of Future: New European Perspectives, traducida al español al año siguiente. Estas publicaciones muestran el gran

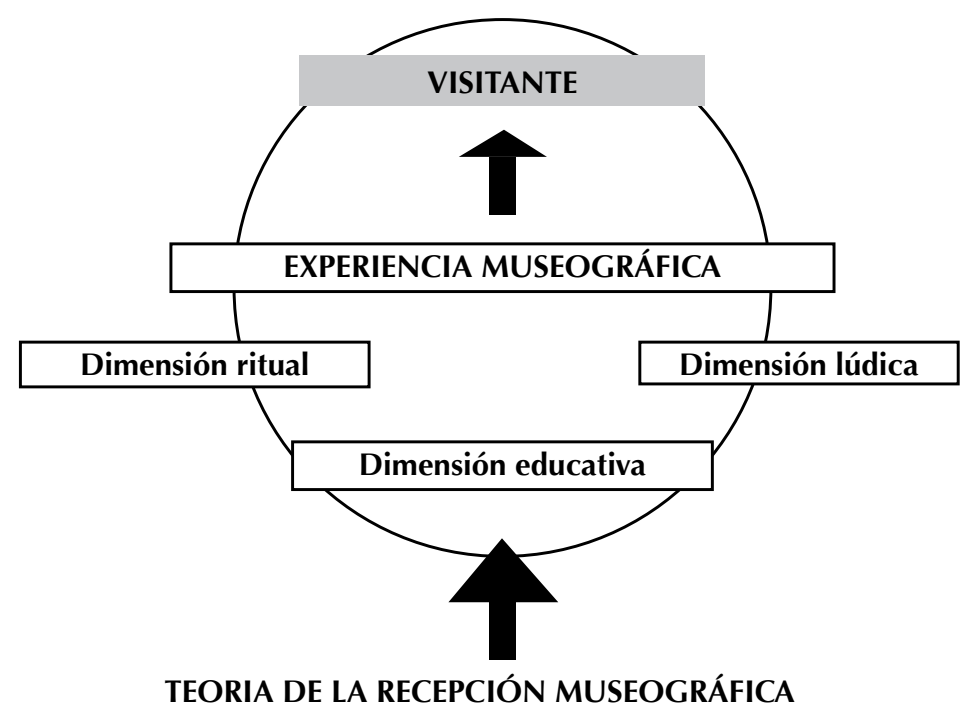

TEORIA DE LA RECEPCIÓN MUSEOGRÁFICA

Modelo paradigmático

Especificidad de la experiencia museográfica

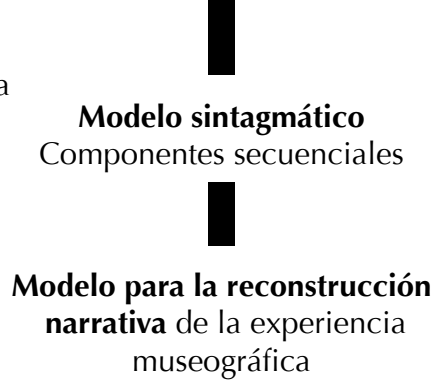

Modelo general

sobre los espacios

FIGURA 2. Diagrama: Ejes reflexivos para abordar la teoría de la recepción museográfica (Ávila Meléndez, 2013). 
interés de la década de los noventa por la comunicación museográfica y el papel del público en los museos.

Es posible que el lector familiarizado con la producción de Zavala se vea tentado a indagar si ha redefinido sus conceptos fundamentales $-\mathrm{O}$ si ha incluido ejemplos actuales-, lo que ocurre solamente en contados casos. Lo que sí es frecuente es que precise algunas de las categorías que nos permiten pensar lo museológico, como es la noción de espacio museográfico que, de acuerdo con él, "es todo espacio donde hay una mirada que reconoce la puesta en escena de conceptos a través de la realización de determinadas actividades físicas, emocionales, intelectuales y estéticas por parte del visitante" (Zavala 2012:24). Si esto es así, y lo museográfico radica en la mirada capaz de reconocer la selección y la exposición de lo sensible, los museos deberían ser, justamente, los espacios para ejercitar y recrear esa mirada, transparentando sus mecanismos de musealización.

\section{Referencias}

Falk, John Howard y Lynn Dianne Dierking 1992 The Museum Experience, Washington, Howells House.

Hooper-Greenhill, Eilean (ed.) 1994 Museums and Their Visitors, Nueva York, Routledge.

1994 The Educational Role of Mu- seum, Nueva York, Routledge.

Miles, Roger y Lauro Zavala (ed.)

1994 Towards the Museum of the Fu-

ture: New European Perspectives,

Nueva York, Routledge.

Zavala, Lauro

2001 "La tendencia transdisciplinaria en los estudios culturales", Folios: Revista de la Facultad de Humanidades, 14: 23-30.

2012 Antimanual del museólogo. Hacia una museología de la vida cotidiana, México, UAM/INAH/Conaculta.

Zavala, Lauro et al. 1993 Posibilidades y límites de la comunicación museográfica, México, UNAM. ICOFOM

2009 Museología: retorno a las bases, ICOFOM (Study Series 38).

\section{Resumen}

Esta reseña sintetiza la propuesta teórica construida por Lauro Zavala a lo largo de 16 años y señala sus tres ejes reflexivos: la valoración del visitante como el patrimonio más valioso; las dimensiones de la experiencia museográfica (lo lúdico, lo ritual y lo educativo), y los modelos transdisciplinares para su estudio (paradigmático, sintagmático, de reconstrucción narrativa y modelo general de los espacios).

Con este libro, los museólogos en formación conocerán a un experto que trabaja "fuera" del campo museístico, quien ha propuesto un enfoque teórico en sincronía con los investigadores que construyeron el "giro comunicativo" en los museos durante la década de 1990, mientras que los profesionales de museos que ya conocían el planteamiento de Zavala podrán evaluar en qué medida el visitante continúa en un segundo plano para la producción museográfica del contexto mexicano o se han creado otras posibilidades de comunicación museográfica centradas en el visitante.

\section{Palabras clave}

teoría de la recepción museográfica; comunicación museográfica; visitante como elemento del patrimonio

\section{Abstract}

This review synthesizes Lauro Zavala's theoretical position constructed over 16 years, by describring its three reflexive axes: the visitors' evaluation as the most valuable heritage, the dimensions of the museographic experience (ludic, ritual and educational) and transdisciplinary models for its study (pragmatic, syntagmatic, narrative reconstruction and general spatial models).

In this book, in-training museologists will meet an expert who works "outside" the field of museology, who has proposed a theoretical approach in synchrony with researchers responsible for the new types of communication models for museums during the 1990s. Meanwhile, museum professionals who are already familiar with Zavala's work will be able to assess to what extent the visitor is still taken for granted within Mexican museographic context or if any other visitor-centered communication possibilities have been created.

\section{Key words}

museum reception theory; museological communication; the visitor as part of the heritage

Título en inglés: Constructing the museographic gaze. Antimanual del museó-

logo by Lauro Zavala

Postulado/Submitted 12.08.2013

Aceptado/Accepted 20.11.2013 